Fetal Diagnosis and Therapy

\title{
Long-Term Neurodevelopmental Outcome of Monochorionic Twins after Laser Therapy or Umbilical Cord Occlusion for Twin-Twin Transfusion Syndrome
}

\author{
Katrine Vasehus Schou ${ }^{\mathrm{a}, \mathrm{b}}$ Ane Vibeke Lando ${ }^{c} \quad$ Charlotte Kvist Ekelund ${ }^{\mathrm{a}}$ \\ Lisa Neerup Jensen ${ }^{a}$ Connie Jørgensen ${ }^{a} \quad$ Lone Nikoline Nørgaard ${ }^{a} \quad$ Line Rode $^{d}$ \\ Kirsten Søgaard ${ }^{a}$ Ann Tabor ${ }^{a, b}$ Karin Sundberg ${ }^{a}$ \\ ${ }^{a}$ Center of Fetal Medicine, Department of Obstetrics, Copenhagen University Hospital Rigshospitalet, Copenhagen, \\ Denmark; ${ }^{b}$ Faculty of Health Sciences, University of Copenhagen, Copenhagen, Denmark; ${ }^{C}$ Department of \\ Neonatology, Copenhagen University Hospital Rigshospitalet, Copenhagen, Denmark; ${ }^{\mathrm{d}}$ Department of Clinical \\ Biochemistry, Herlev and Gentofte Hospital, Gentofte, Denmark
}

\section{Keywords}

Ages and Stages Questionnaires · Cerebral palsy ·

Fetoscopic selective laser coagulation · Long-term follow-up · Monochorionic twins · Neurodevelopmental impairment - Twin-twin transfusion syndrome - Twin control group · Umbilical cord occlusion

\footnotetext{
Abstract

Introduction: We sought to assess the incidence of severe neurodevelopmental impairment (NDI) in monochorionic twins treated for twin-twin transfusion syndrome (TTTS) and compare it to the incidence in uncomplicated monochorionic twins. Material and Methods: We included TTTS pregnancies treated by fetoscopic selective laser coagulation (FSLC) or umbilical cord occlusion (UCO) in 2004-2015. Primary outcome was severe NDI defined as cerebral palsy, bilateral blindness or bilateral deafness (ICD-10 diagnoses), and severe cognitive and/or motor delay (assessed by the Ages and Stages Questionnaires [ASQ]). Results: A total of 124 children after TTS and 98 controls were followed up at 25 months of age (SD 11.4). Severe NDI was found in $8.9 \%$ of
}

the TTTS children (10.5\% [9/86] after FSLC; 5.3\% [2/38] after UCO) compared to $3.1 \%$ in the control group ( $p=0.10)$. The odds ratio for severe NDI was 1.8 in cases versus controls $(p=0.37)$. The total ASQ score was significantly lower in the TTTS group than in controls $(p=0.03)$ after FSLC $(p=0.03)$ and after UCO ( $p=0.14)$. Discussion: Children after TTTS appear to have a higher risk of severe NDI and score significantly lower on the ASQ compared to monochorionic twins from uncomplicated pregnancies.

๑ 2018 S. Karger AG, Basel

\section{Introduction}

Monochorionicity in twin pregnancies is associated with a high risk of fetal mortality and morbidity [1]. Twin-twin transfusion syndrome (TTTS) affects around $10-15 \%$ of monochorionic (MC) pregnancies and is characterized by an unequal blood distribution due to inter-twin anastomoses in the shared placenta leaving one twin as a donor and the co-twin as a recipient [2-4]. Untreated TTTS leads to an up to $90 \%$ risk of

\section{KARGER}

(c) 2018 S. Karger AG, Basel

E-Mail karger@karger.com

www.karger.com/fdt
Katrine Vasehus Schou, MD

Center of Fetal Medicine, Department of Obstetrics

Rigshospitalet, Copenhagen University Hospital

Blegdamsvej 9, DK-2100 Copenhagen (Denmark)

E-Mail katrinevasehus@gmail.com 
spontaneous death of one or both twins $[3,5,6]$. In case of spontaneous death of one MC twin, the risk for neurological abnormality in the surviving co-twin is around $18 \%$ [7].

Fetoscopic laser coagulation of inter-twin anastomoses by various techniques is considered the gold standard treatment of TTTS $[3,5,8,9]$. Selective feticide is another treatment option in certain cases [10-15]. Studies on the long-term neurodevelopmental outcome in children after TTTS are still limited, especially after selective feticide of the co-twin [11, 15-17]. Severe neurodevelopmental impairment (NDI) is reported to occur in 8-15\% $[11,15,17,18]$ of children after fetoscopic laser surgery or selective feticide and is believed to be influenced by TTTS itself [19], gestational age (GA) at delivery, and birthweight [20]. Some studies suggest that twinning and monochorionicity may increase the risk of neurologic disabilities [21-23]. The aim of this study was to assess the risk of severe NDI in MC twins treated for TTTS by either fetoscopic selective laser coagulation (FSLC) or selective feticide by ultrasound-guided umbilical cord occlusion (UCO) in a consecutive Danish national cohort and to compare the incidence of severe NDI with a control group of MC twins from uncomplicated pregnancies.

\section{Material and Methods}

\section{Study Population}

All MC twin pregnancies with TTTS undergoing FSLC or ultrasound-guided UCO at Rigshospitalet in Copenhagen, Denmark, from 2004 to 2015 were included in our cohort. TTTS was classified according to the Quintero stages I-IV [24]. The surgical techniques of FSLC and ultrasound-guided UCO are described in earlier reports $[14,25]$. The following obstetrical data were recorded; type of surgery, Quintero stage, GA at procedure, GA at birth, date of birth, birthweight, and sex. Maternal educational level at follow-up was also recorded, determined by the mother's (1) highest completed level in school (1-4 points) and (2) further education/employment (1-4 points); 8 points referred to the highest educational level.

\section{Approvals}

The study was approved by the local Data Protection Agency (j.nr: 2012-58-0004). Permission from the Ethics Committee is not required for questionnaire studies in Denmark. All parents gave oral and written consent for follow-up at the time of surgery. Oral consent was re-obtained when inviting parents to the follow-up in 2008-2017.

\section{Primary Outcome}

Our primary outcome was severe NDI defined as a composite of at least 1 of the following conditions: cerebral palsy (CP), bilateral blindness, bilateral deafness (assessed by the WHO Interna- tional Classification of Diseases [ICD-10] codes registered in the Danish National Patients' Register, retrieved April 2015), and severe cognitive and/or motor delay (assessed by the Ages and Stages Questionnaires second edition [ASQ-II]) [19].

\section{The Ages and Stages Questionnaires}

The ASQ is a series of parent-completed questionnaires aimed at estimating the developmental status of young children [26]. The questionnaires have been translated into Danish with permission from the author [27].

They consist of 5 domains: communication, gross motor skills, fine motor skills, problem solving, and personal-social skills with 6 questions for each domain and 3 possible answers; "yes" (10 points), "sometimes" (5 points), and "not yet" (0 points), yielding an overall maximum score of 300 points. An ASQ score below the mean -2 standard deviations (SD) is an indicator of severe delay in the psycho-motoric development [26-28]. We used the ASQ-II at $18,24,33,48$, and 60 months in the TTTS group and at 24 months in the control group. The due dates were used to calculate age to correct for prematurity. Better-than-average children tend to score the maximum on ASQ tests $[27,29]$; therefore, children 1-2 years of age got a questionnaire for 6 months older children. Children aged 3 and 4 years got a questionnaire for children 1 year older.

\section{Telephone Interviews}

As children older than 60 months could not be screened by the ASQ-II, maternal telephone interviews were done using a guide (see online suppl. Table S2; for all online suppl. material, see www. karger.com/doi/10.1159/000491787). Only children with CP, bilateral blindness, or deafness were included in the overall assessment.

\section{The Control Group}

The control group consisted of uncomplicated Danish MC twins derived from a Danish-Austrian randomized clinical trial examining the effect of vaginal progesterone treatment on the prevention of preterm delivery in twin pregnancies [30]. The children were followed up from 2008 to 2010 at age 18 months by the ASQ24. From April to November 2014, ICD-10 diagnoses of the children were retrieved from hospital records [31]. Cases developing TTTS were excluded $(n=3)$.

\section{Statistical Analysis}

All statistical analyses were conducted using SAS. Numbers (percentages), means $\pm \mathrm{SD}$, and medians (ranges) are reported as appropriate. The intervention group in total and stratified by type of surgery (FSLC vs. UCO) and by GA at birth $<34$ or $\geq 34$ weeks was compared to the control group using Fisher's exact test, MannWhitney $U$ test, and a linear regression analysis in a mixed model, as appropriate. Children with ASQ data and a CP diagnosis $(n=3)$ were excluded from the ASQ analyses but were included in the overall NDI assessment. Mean -2 SD of the pooled total ASQ score in the control group was used as a cutoff for severe NDI. Multiple logistic regression analysis was used to calculate odds ratios (OR) for impairment. The statistical analyses were adjusted for the relatedness of twins and for confounders: age at follow-up; ASQ form; GA at birth; birthweight; sex, and maternal education, as appropriate $[20,22,32]$. 
Table 1. Distribution of children by long-term follow-up methods

\begin{tabular}{|c|c|c|c|}
\hline Follow-up method & $\begin{array}{l}\text { Controls, } n \\
(n=100)\end{array}$ & $\begin{array}{l}\text { FSLC, } n \\
(n=122)\end{array}$ & $\begin{array}{l}\mathrm{UCO}, n \\
(n=54)\end{array}$ \\
\hline ASQ + ICD-10 diagnoses & 86 & 55 & 33 \\
\hline ASQ alone & - & 13 & 5 \\
\hline ICD-10 diagnoses alone & 12 & 16 & 2 \\
\hline Telephone interview + ICD-10 diagnoses & - & 16 & 7 \\
\hline Not included in the follow-up & $\begin{array}{l}2 \\
\text { Did not respond } \\
\text { to ASQ, } n=2\end{array}$ & $\begin{array}{l}22 \\
\text { Death from ileus } 8 \text { months old, } n=1 \\
\text { Lack of Danish skills, } n=1 \\
\text { Other Scandinavians, } n=14 \\
\text { Did not respond to ASQ, } n=6\end{array}$ & $\begin{array}{l}7 \\
\text { Death from volvulus } 10 \text { months } \\
\text { old, } n=1 \\
\text { Lack of Danish skills, } n=1 \\
\text { Other Scandinavians, } n=4 \\
\text { Did not respond to ASQ, } n=1\end{array}$ \\
\hline
\end{tabular}

n, number of children; FSLC, fetoscopic selective laser coagulation; UCO, ultrasound-guided umbilical cord occlusion; ASQ, Ages and Stages Questionnaires; ICD-10 diagnoses, The WHO International Classification of Diseases.

Table 2. Characteristics and primary outcome of the study and control groups

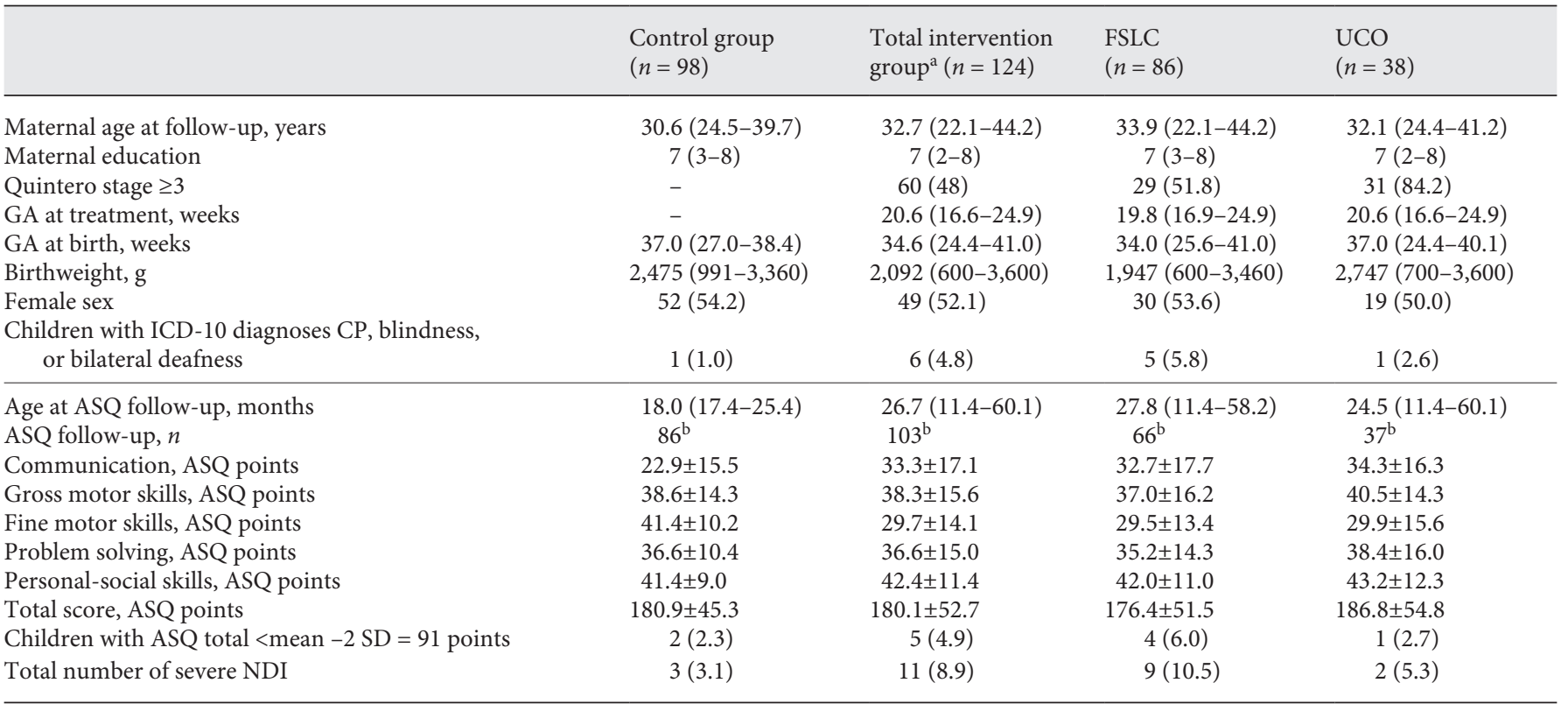

Data are reported as $n(\%)$; median (range); and mean \pm SD, as appropriate. FSLC, fetoscopic selective laser coagulation; UCO, umbilical cord occlusion; GA, gestational age; CP, cerebral palsy; ASQ, The Ages and Stages Questionnaires; SD, standard deviation; NDI, neurodevelopmental impairment. ${ }^{a}$ Children from pregnancies with twin-twin transfusion syndrome treated by FSLC or UCO. ${ }^{\mathrm{b}}$ The cases of cerebral palsy have been excluded.

\section{Results}

A total of $131 \mathrm{MC}$ twin pregnancies with TTTS (176 children) were eligible for long-term follow-up. The lostto-follow-up rate was $14.5 \%$ (19/131 pregnancies). Table 1 shows the distribution of children by mode of treatment and follow-up methods and the distribution of children lost to follow-up. Maternal and obstetrical characteristics are shown in Table 2. GA at birth and birthweight were significantly lower in the intervention group than in the control group (median GA at birth 34.6 vs. 37.0 weeks, $p=0.03$; median birthweight 2,092 vs. $2,475 \mathrm{~g}, p=0.004$ ). 
Table 3. The distribution of severe NDI according to GA at birth

\begin{tabular}{|c|c|c|c|c|}
\hline GA at birth & Controls $(n=48)$ & TTTS $(n=94)$ & FSLC $(n=56)$ & $\mathrm{UCO}(n=38)$ \\
\hline$<34$ weeks & 7 & 36 & 26 & 10 \\
\hline Cerebral palsy & $1(14.3)$ & $4(11.1)$ & $4(15.4)$ & - \\
\hline ASQ score $<$ mean -2 SD & $1(14.3)$ & $3(8.3)$ & $2(7.7)$ & $1(10)$ \\
\hline Normal development & $5(71.5)$ & $29(80.6)$ & $20(76.9)$ & $9(90)$ \\
\hline$\geq 34$ weeks & 41 & 58 & 30 & 28 \\
\hline Cerebral palsy & - & $2(3.4)$ & $1(3.3)$ & $1(3.6)$ \\
\hline ASQ score $<$ mean -2 SD & $1(2.4)$ & $1(1.7)$ & $1(3.3)$ & - \\
\hline Normal development & $40(97.6)$ & $55(94.8)$ & $28(93.3)$ & $27(96.4)$ \\
\hline
\end{tabular}

Values are $n$ (\%). NDI, neurodevelopmental impairment; GA, gestational age; TTTS, twin-twin transfusion syndrome; FSLC, fetoscopic laser coagulation; UCO, umbilical cord occlusion; SD, standard deviation; ASQ, Ages and Stages Questionnaires.

Stratified by treatment method, the UCO group had more pregnancies classified in Quintero stage $\geq 3$ ( 84 vs. $51 \%$, $p=0.003)$, a higher median GA at birth (37.0 vs. 34.0 weeks, $p=0.006)$, and a higher median birthweight $(2,747$ vs. $1,947 \mathrm{~g}, p=0.003$ ) compared to the FSLC group. Otherwise, the 2 intervention groups had similar baseline characteristics. One twin pair in the FSLC group had congenital cytomegalovirus.

\section{Primary Outcome}

The incidence of severe NDI was $8.9 \%(11 / 124)$ in children after intervention (6 children with a CP diagnosis and 5 children with an ASQ score below the cutoff) compared to $3.1 \%(3 / 98)$ in the children from the control group ( 1 child with CP and 2 with ASQ scores below the cutoff, $p=0.10$; Table 2). Multiple logistic regression analysis yielded an OR of 3.0 (95\% confidence interval [CI $0.8-11.2, p=0.10$ ) for severe NDI in cases compared to controls adjusted for relatedness in twins. Adding GA at birth, birthweight, and sex to the model, the OR was 1.8 (95\% CI 0.5-7.1, $p=0.38$ ). Table 3 displays cases with severe NDI in the different study groups with GA at birth $<34$ or $\geq 34$ weeks.

Stratified into treatment groups, 9 children (10.5\%) had severe NDI after FSLC and 2 children had severe NDI after UCO (5.3\%) compared to 3 children $(3.1 \%)$ in the control group ( $p=0.07$ and $p=0.62$, respectively). There was no difference in NDI rates within the FSLC group stratified by pregnancies with 1 versus 2 alive born neonates ( 8.3 vs. $11.3 \%, p=1.0$ ).

\section{ASQ Results}

A total of 106 children from TTTS pregnancies and 86 controls were followed up with the ASQ. Median age at follow-up was higher in the intervention group than in the control group: 26.7 (range 11.4-60.1) and 18.0 (range 17.4-25.4) months, respectively $(p<0.0001)$ (Table 2). The unadjusted total ASQ score was $176.3 \pm$ 56.9 in the intervention group and $180.9 \pm 45.3$ in the control group ( $p=0.5$ ) (Table 2). The cutoff of $2 \mathrm{SD}$ subtracted from the mean was 91 points. The twin couple with congenital cytomegalovirus scored 115 and 135 points, respectively. The child with $\mathrm{CP}$ in the control group was not followed up by the ASQ. After exclusion of the CP cases, the mean total score in the intervention group was $180.1 \pm 52.7$. When excluding the CP cases and adjusting for relatedness in twins, age at follow-up, ASQ form, birthweight, sex, and maternal education, the control group had higher scores in all domains, but this was only significant in the "fine motor" domain ( $p=0.0005)$ and in the ASQ total score $(-25.9$ points, $95 \% \mathrm{CI}-45.4$ to $-6.4, p=0.01$ ). Children from the FSLC treatment group had significantly lower estimates than controls ( -23.5 points, $95 \%$ CI -44.8 to $-2.2, p=0.03$ ). Children after UCO had lower estimates, as well, but not significantly different from the controls $(-19.4$ points, $95 \%$ CI -45.6 to $6.8, p=0.14$ ). Table 4 sums up the ASQ scores with and without the children with CP. A subanalysis on children followed up by the ASQ for 24 months confirmed the lower estimates in the intervention group (ASQ total score -21.3 points, 95\% CI -46.3 to $3.6, p=0.09)$.

\section{Diagnoses}

In the TTTS group, $4.8 \%(6 / 124)$ of the children had CP (5.8\% after FSLC and $2.6 \%$ after UCO) compared to $1 \%(1 / 98)$ in the control group $(p=0.14)$. Two children with $\mathrm{CP}$ also had bilateral hearing loss. No children were 
Table 4. Linear regression analyses comparing ASQ scores between intervention group and control group

\begin{tabular}{|c|c|c|c|c|}
\hline \multirow[t]{2}{*}{ ASQ domain } & \multicolumn{2}{|c|}{$\begin{array}{l}\text { All ASQ data on all children in the intervention } \\
\text { group compared to controls }\end{array}$} & \multicolumn{2}{|c|}{$\begin{array}{l}\text { ASQ data where children with CP are } \\
\text { removed before analysis }\end{array}$} \\
\hline & $\begin{array}{l}\text { estimate }(\mathrm{CI})^{\mathrm{a}} \\
p \text { value }\end{array}$ & $\begin{array}{l}\text { estimate }(\mathrm{CI})^{\mathrm{b}} \\
p \text { value }\end{array}$ & $\begin{array}{l}\text { estimate }(\mathrm{CI})^{\mathrm{a}} \\
p \text { value }\end{array}$ & $\begin{array}{l}\text { estimate }(\mathrm{CI})^{\mathrm{b}} \\
p \text { value }\end{array}$ \\
\hline Communication & $\begin{array}{l}-0.3(-5.9 \text { to } 5.3) \\
p=0.92\end{array}$ & $\begin{array}{l}-1.0(-6.8 \text { to } 4.8) \\
p=0.72\end{array}$ & $\begin{array}{l}0.3(-5.3 \text { to } 6.0) \\
p=0.91\end{array}$ & $\begin{array}{l}-0.8(-6.6 \text { to } 5.0) \\
p=0.78\end{array}$ \\
\hline Fine motor & $\begin{array}{l}-12.5(-18.0 \text { to }-6.9) \\
p<0.0001\end{array}$ & $\begin{array}{l}-9.5(-14.8 \text { to }-4.2) \\
p=0.001\end{array}$ & $\begin{array}{l}-10.8(-16.3 \text { to }-5.3) \\
p=0.0002\end{array}$ & $\begin{array}{l}-10.2(-15.9 \text { to }-4.6) \\
p=0.0005\end{array}$ \\
\hline Problem solving & $\begin{array}{l}-6.1(-11.3 \text { to }-0.9) \\
p=0.02\end{array}$ & $\begin{array}{l}-6.2(-11.9 \text { to }-0.6) \\
p=0.03\end{array}$ & $\begin{array}{l}-4.9(-10.1 \text { to } 0.3) \\
p=0.07\end{array}$ & $\begin{array}{l}-5.4(-11.0 \text { to } 0.1) \\
p=0.06\end{array}$ \\
\hline Personal-social & $\begin{array}{l}-5.3(-9.6 \text { to }-1.1) \\
p=0.01\end{array}$ & $\begin{array}{l}-5.2(-9.6 \text { to }-0.9) \\
p=0.02\end{array}$ & $\begin{array}{l}-3.9(-8.0 \text { to } 0.1) \\
p=0.06\end{array}$ & $\begin{array}{l}-3.9(-8.1 \text { to } 0.2) \\
p=0.06\end{array}$ \\
\hline
\end{tabular}

The analyses were performed using a mixed model in SAS. ASQ, Ages and Stages Questionnaires; CP, cerebral palsy; CI, confidence interval. ${ }^{\text {a }}$ Adjusted for the relatedness in twins and age at follow-up in months. ${ }^{\text {b }}$ Adjusted for the relatedness in twins, age at follow-up in months, ASQ form, sex, birthweight, and maternal education.

Table 5. Overview of the children diagnosed with cerebral palsy

\begin{tabular}{llllllll}
\hline Diagnosis & $\begin{array}{l}\text { TTTS } \\
\text { stage }\end{array}$ & $\begin{array}{l}\text { Type of } \\
\text { surgery }\end{array}$ & $\begin{array}{l}\text { GA at } \\
\text { delivery }\end{array}$ & $\begin{array}{l}\text { Birth } \\
\text { weight, g }\end{array}$ & Sex & $\begin{array}{l}\text { Total ASQ } \\
\text { score }\end{array}$ & Details \\
\hline Tetraplegic cerebral palsy & 3 & FSLC & 29.9 & 1,678 & Male & 0 & $\begin{array}{l}\text { Neonatal grade III IVH } \\
\text { IUFD of co-twin 23.7 weeks, } 4 \text { weeks after } \\
\text { FSLC }\end{array}$ \\
\hline Tetraplegic cerebral palsy & 3 & FSLC & 37.6 & 2,280 & Male & - & IUFD of co-twin the day after FSLC \\
\hline Tetraplegic cerebral palsy & 1 & FSLC & 33.9 & 2,240 & Male & - & Co-twin live born \\
\hline Diplegic cerebral palsy & 3 & FSLC & 30.3 & 1,564 & Female & 60 & $\begin{array}{l}\text { Neonatal grade I IVH } \\
\text { Co-twin live born }\end{array}$ \\
\hline Hemiplegic cerebral palsy & 3 & FSLC & 26.3 & 600 & Female & $\begin{array}{l}\text { Telephone } \\
\text { interview }\end{array}$ & $\begin{array}{l}\text { Neonatal grade III IVH } \\
\text { Bilateral conductive and perceptive } \\
\text { hearing loss and deaf on left ear } \\
\text { Neonatal death of co-twin }\end{array}$ \\
\hline Ataxic cerebral palsy & 4 & UCO & 34.7 & 2,050 & Male & 75 & Hearing loss (not specified) \\
\hline Tetraplegic cerebral palsy & - & Control & 29.9 & 1,020 & Male & - & Co-twin live born
\end{tabular}

TTTS, twin-twin transfusion syndrome; GA, gestational age; ASQ, Ages and Stages Questionnaires; FSLC, fetoscopic selective laser coagulation; IVH, intraventricular hemorrhage; IUFD, intrauterine fetal death; UCO, umbilical cord occlusion.

blind in either group. Table 5 shows details about the children with CP. The children's age at the time of retrieving diagnoses was 18 months to 10 years in the intervention group and 5-8 years in the control group.

\section{Telephone Interviews}

There were 23 children followed up by telephone interviews. One child had CP and was accounted for in the overall assessment. Two-thirds of the mothers reported "problems during early childhood." In most cases, the 
child/children had caught up at the time of the interview. The incidence of developmental delay and ongoing problems at follow-up was $17.4 \%$ (4/23) (see online suppl. Table S1, which sums up the interviews, and online suppl. Table S2, which displays the interview guide).

\section{Discussion}

The overall outcome of severe NDI was $8.9 \%$ in the children after invasively treated TTTS compared to 3.1\% in the control group of uncomplicated MC twins. The incidence was $10.5 \%$ in the FSLC group and $5.3 \%$ in the UCO group.

A newly published systematic review sums up studies on outcome in 24-month-old children after TTTS and finds a mean incidence of neurological anomalies after FSLC of $14.1 \%$ [18]. Sananès et al. [33] used ASQ and neurological evaluation and found NDI in $13.5 \%$ of 126 children after FSLC. Moreover, they found 8 fetuses with significant brain lesions on pre- or postnatal ultrasound or MRI; only 1 child from these pregnancies was alive at 3 years of age and had CP [33]. Another study used ASQ and other neurological evaluation tools to follow up children after FSLC and reported an overall rate of major neurological abnormalities, including CP of $12 \%$ [34].

The long-term outcome after selective feticide in MC twin pregnancies was studied by van Klink et al. [15] who found a CP incidence of $2.6 \%(2 / 74)$ and an overall NDI rate of $6.8 \%$. Another follow-up study of children aged 1-6 years presented 1 child with CP $(2 \%)$, and $6 \%$ of the children had mild impairment after selective feticide [11]. Our rates of CP and severe NDI after selective feticide are similar to the cited studies' rates $(2.6 \% \mathrm{CP}$ and $5.3 \%$ overall NDI), although they report outcome after surgery for various indications, including severe discordant anomalies where you might expect a lower risk of impairment for the survivor twin. Likewise, our results seem in line with the studies on outcome after FSLC, although our overall NDI rate is a little lower (10.5 compared to $14.1 \%$ ). A plausible explanation is the larger proportion of Quintero stage 3-4 in the cited studies on FSLC. In our population, more Quintero stage 3-4 twins are treated by UCO. Based on our results, children after UCO seem to have a lower rate of severe NDI and CP than children born after FSLC treatment despite the higher proportion of Quintero stage 3-4. One explanation could be that the children after FSLC are born at a lower GA with lower birthweights. Although Table 3 displays that GA at birth is not the only influential factor for NDI, CP and a low

Long-Term Outcome after Invasive

Treatment of TTTS
ASQ score were also found in children born after 34 weeks. Another explanation could be that the fetuses with the worst expected outcome are selected for feticide, thereby minimizing the rate of $\mathrm{CP}$ in the UCO group. We did not find a significant difference in NDI between the FSLC and the UCO group, which may be due to the sample size. Prenatal MRI or neurosonography was not offered routinely in our setting. Such examinations might be useful in detecting fetuses with signs of neurological injury [35] and may become state of the art in the followup after any invasive treatment of TTTS.

Among the children followed up at school age by telephone interviews, $17.4 \%$ (4/23) had developmental delay and behavioral problems or learning disabilities. Although it was excluded from our overall analysis, we report this outcome, since it adds important information on possible long-term behavioral difficulties in these children, as mentioned by others $[15,21]$. It should be noted that the interviews were performed in a small selected group of children lost to follow-up by the ASQ, hypothetically due to the lack of skills expected for their age $[15,36,37]$.

It has been shown that $\mathrm{MC}$ twins have a higher rate of NDI [22] than the general population. In our study, the $\mathrm{CP}$ rate was $1 \%$ in the control group compared to $0.24 \%$ in the general Danish population [38]. This emphasizes the strength of using a control group of MC twins. If mean -2 SD deviations from singleton ASQ references [27, 39] had been used, there would be a risk of overestimating the NDI rate and camouflaging the role of TTTS in NDI. Our control group of normally developing MC twins allows removal of this risk of overestimation.

The mixed follow-up methods could be considered a limitation, but by adding ICD-10 diagnoses, 2 extra children with $\mathrm{CP}$ were identified, who were otherwise lost to follow-up by the ASQ. The heterogeneity in age at ASQ follow-up in the intervention group is a limitation that is adjusted for in the statistical analyses. We used 5 of the available ASQ-IIs as a compromise between using a questionnaire appropriate for age and the statistical problem of using many different questionnaires as was done by others [27]. Another limitation is the sample size, which is a general problem in long-term studies of MC twins.

Our results support the hypothesis that GA at birth and birthweight are essential factors for the outcome of children born from MC twin pregnancies. Moreover, MC twinning seems to increase the risk of severe NDI, especially when complicated by TTTS. This underlines the importance of a twin control group in future follow-up studies. Follow-up at school age in a reproducible setting would be advisable. 
In conclusion, we found a trend towards an increased incidence of severe NDI in MC twins after invasive treatment of TTTS. There was a significant difference in the overall ASQ scores between the TTTS group and controls and between the children from the FSLC group and controls. The difference between the UCO group and controls was nonsignificant.

\section{Disclosure Statement}

The authors report no conflicts of interest.

\section{References}

1 Sepulveda W: Chorionicity determination in twin pregnancies: double trouble. Ultrasound Obstet Gynecol 1997;10:79-81.

2 Lewi L, Deprest J, Hecher K: The vascular anastomoses in monochorionic twin pregnancies and their clinical consequences. Am J Obstet Gynecol 2013;208:19-30.

3 Diehl W, Diemert A, Hecher K: Twin-twin transfusion syndrome: treatment and outcome. Best Pract Res Clin Obstet Gynaecol 2014;28:227-238.

4 Simpson LL: Twin-twin transfusion syndrome. Am J Obstet Gynecol 2013;208:3-18.

5 Moldenhauer JS, Johnson MP: Diagnosis and management of complicated monochorionic twins. Clin Obstet Gynecol 2015;58: 632-642.

6 Lewi L, Jani J, Blickstein I, Huber A, Gucciardo L, Van Mieghem T, Done E, Boes AS, Hecher K, Gratacos E, Lewi P, Deprest J: The outcome of monochorionic diamniotic twin gestations in the era of invasive fetal therapy: a prospective cohort study. Am J Obstet Gynecol 2008;199:514.e511-e518.

7 Hillman SC, Morris RK, Kilby MD: Co-twin prognosis after single fetal death: a systematic review and meta-analysis. Obstet Gynecol 2011;118:928-940.

8 Quintero RA, Kontopoulos E, Chmait RH: Laser treatment of twin-to-twin transfusion syndrome. Twin Res Hum Genet 2016;19: 197-206.

9 Slaghekke F, Oepkes D: Solomon technique versus selective coagulation for twin-twin transfusion syndrome. Twin Res Hum Genet 2016;19:217-221.

10 Bebbington M: Selective reduction in complex monochorionic gestations. Am J Perinatol 2014;31(suppl 1):S51-S58.

11 Lewi L, Gratacos E, Ortibus E, Van Schoubroeck D, Carreras E, Higueras T, Perapoch J, Deprest J: Pregnancy and infant outcome of 80 consecutive cord coagulations in complicated monochorionic multiple pregnancies. Am J Obstet Gynecol 2006;194:782-789.

12 Rossi AC, D’Addario V: Umbilical cord occlusion for selective feticide in complicated monochorionic twins: a systematic review of literature. Am J Obstet Gynecol 2009;200: 123-129.
13 Lanna MM, Rustico MA, Dell'Avanzo M, Schena V, Faiola S, Consonni D, Righini A, Scelsa B, Ferrazzi EM: Bipolar cord coagulation for selective feticide in complicated monochorionic twin pregnancies: 118 consecutive cases at a single center. Ultrasound Obstet Gynecol 2012;39:407-413.

14 Schou KV, Jensen LN, Jorgensen C, Sogaard K, Tabor A, Sundberg K: Ultrasound-guided bipolar umbilical cord occlusion in complicated monochorionic pregnancies: is there a learning curve. Fetal Diagn Ther 2018;44:6571.

15 van Klink J, Koopman HM, Middeldorp JM, Klumper FJ, Rijken M, Oepkes D, Lopriore E: Long-term neurodevelopmental outcome after selective feticide in monochorionic pregnancies. BJOG 2015;122:1517-1524.

16 Ortibus E, Lopriore E, Deprest J, Vandenbussche FP, Walther FJ, Diemert A, Hecher K, Lagae L, De Cock P, Lewi PJ, Lewi L: The pregnancy and long-term neurodevelopmental outcome of monochorionic diamniotic twin gestations: a multicenter prospective cohort study from the first trimester onward. Am J Obstet Gynecol 2009;200:494.e491-e498.

17 Campos D, Arias AV, Campos-Zanelli TM, Souza DS, Dos Santos Neto OG, Peralta CF, Guerreiro MM: Twin-twin transfusion syndrome: neurodevelopment of infants treated with laser surgery. Arq Neuropsiquiatr 2016; 74:307-313.

18 Miralles-Gutierrez A, Narbona-Arias I, Gonzalez-Mesa E: Neurological complications after therapy for fetal-fetal transfusion syndrome: a systematic review of the outcomes at 24 months. J Perinat Med 2017, Epub ahead of print.

19 van Klink JM, Koopman HM, Rijken M, Middeldorp JM, Oepkes D, Lopriore E: Longterm neurodevelopmental outcome in survivors of twin-to-twin transfusion syndrome. Twin Res Hum Genet 2016;19:255-261.

20 Lorenz JM: Neurodevelopmental outcomes of twins. Semin Perinatol 2012;36:201-212.

21 Sierakowski A, Eapen V, Crncec R, Smoleniec $\mathrm{J}$ : Developmental and behavioral outcomes of uncomplicated monochorionic diamniotic twins born in the third trimester. Neuropsychiatr Dis Treat 2017;13:1373-1384.
22 Nan C, Piek J, Warner C, Mellers D, Krone RE, Barrett T, Zeegers MP: Trajectories and predictors of developmental skills in healthy twins up to 24 months of age. Infant Behav Dev 2013;36:670-678.

23 Adegbite AL, Castille S, Ward S, Bajoria R: Neuromorbidity in preterm twins in relation to chorionicity and discordant birth weight. Am J Obstet Gynecol 2004;190:156-163.

24 Quintero RA, Morales WJ, Allen MH, Bornick PW, Johnson PK, Kruger M: Staging of twin-twin transfusion syndrome. J Perinatol 1999; 19:550-555.

25 Sundberg K, Sogaard K, Jensen LN, Schou $\mathrm{KV}$, Jorgensen C: Invasive treatment in complicated monochorionic twin pregnancies: indications and outcome of 120 consecutively treated pregnancies. Acta Obstet Gynecol Scand 2012;91:1201-1205.

26 Squires J, Bricker D, Potter L: Revision of a parent-completed development screening tool: Ages and Stages Questionnaires. J Pediatr Psychol 1997;22:313-328.

27 Plomgaard AM, Hansen BM, Greisen G: Measuring developmental deficit in children born at gestational age less than 26 weeks using a parent-completed developmental questionnaire. Acta Paediatr 2006;95:1488-1494.

28 Skellern CY, Rogers Y, O'Callaghan MJ: A parent-completed developmental questionnaire: follow up of ex-premature infants. J Paediatr Child Health 2001;37:125-129.

29 Vandborg PK, Hansen BM, Greisen G, Jepsen M, Ebbesen F: Follow-up of neonates with total serum bilirubin levels $>/=25 \mathrm{mg} / \mathrm{dL}$ : a Danish population-based study. Pediatrics 2012;130:61-66.

30 Rode L, Klein K, Nicolaides KH, Krampl-Bettelheim E, Tabor A: Prevention of preterm delivery in twin gestations (PREDICT): a multicenter, randomized, placebo-controlled trial on the effect of vaginal micronized progesterone. Ultrasound Obstet Gynecol 2011;38:272-280.

31 Vedel C, Larsen H, Holmskov A, Andreasen KR, Uldbjerg N, Ramb J, Bodker B, Skibsted L, Sperling L, Krebs L, Zingenberg H, Laursen L, Christensen JT, Tabor A, Rode L: Longterm effects of prenatal progesterone exposure: neurophysiological development and hospital admissions in twins up to 8 years of age. Ultrasound Obstet Gynecol 2016;48: 382-389. 
32 Kawamura H, Ishii K, Yonetani N, Mabuchi A, Hayashi S, Mitsuda N: Significance of chorionicity on long-term outcome of low birthweight infants of $<1,500 \mathrm{~g}$ in twin pregnancies. J Obstet Gynaecol Res 2015;41:11851192.

33 Sananès N, Gabriele V, Weingertner AS, Ruano R, Sanz-Cortes M, Gaudineau A, Langer B, Nisand I, Akladios CY, Favre R: Evaluation of long-term neurodevelopment in twin-twin transfusion syndrome after laser therapy. Prenat Diagn 2016;36:1139-1145.
34 Salomon LJ, Ortqvist L, Aegerter P, Bussieres L, Staracci S, Stirnemann JJ, Essaoui M, Bernard JP, Ville Y: Long-term developmental follow-up of infants who participated in a randomized clinical trial of amniocentesis vs laser photocoagulation for the treatment of twin-to-twin transfusion syndrome. Am J Obstet Gynecol 2010;203:444.e441-447.

35 Robinson A, Teoh M, Edwards A, Fahey M, Goergen S: Fetal brain injury in complicated monochorionic pregnancies: diagnostic yield of prenatal MRI following surveillance ultrasound and influence on prognostic counselling. Prenat Diagn 2017;37:611-627.
36 Wariyar UK, Richmond S: Morbidity and preterm delivery: importance of $100 \%$ followup. Lancet 1989;1:387-388.

37 Aylward GP, Hatcher RP, Stripp B, Gustafson NF, Leavitt LA: Who goes and who stays: subject loss in a multicenter, longitudinal followup study. J Dev Behav Pediatr 1985;6:3-8.

38 Colver A, Fairhurst C, Pharoah PO: Cerebral palsy. Lancet 2014;383:1240-1249.

39 Squires J, Potter L, Bricker D: The ASQ User's Guide for the Ages and Stages Questionnaires: A Parent-Completed, Child-Monitoring System, ed 2. Paul H Brookes Publishing Co, Inc, 1999, p 41 